\title{
Villa Muñecas: \\ El deterioro laboral y social que generó el cierre de los ingenios y la partida del tren
}

\author{
Alejandra del Castillo ${ }^{1}$ \\ delcale@hotmail.com \\ Ariel Osatinsky \\ aosatinsky@yahoo.com.ar \\ Rec. 20/02 2018 Apr. 25/04 2018
}

\begin{abstract}
Resumen
Este artículo describe las características que asume la pobreza en Villa Muñecas, un barrio de Gran San Miguel de Tucumán, analizando los procesos que determinaron el pasaje de un barrio obrero a un área de privación. Los interrogantes que guían su desarrollo son ¿Cómo incidieron las transformaciones económicas, sociales y territoriales en el devenir histórico de Villa Muñecas? ¿Cuáles son las manifestaciones actuales de la pobreza en esta área? ¿Qué cambios se observan en las configuraciones de la pobreza? Se realiza un estudio de caso centrado en dimensiones vinculadas al trabajo y al hábitat teniendo en cuenta el devenir histórico.
\end{abstract}

Palabras claves: deterioro laboral - pobreza - hábitat - Villa Muñecas.

\begin{abstract}
This paper describes the characteristics that poverty adopts in Villa Muñecas, a slum in the Gran San Miguel de Tucumán region, by analysing the processes that determined the transition from a working class borough to an area of deprivation. The questions that guide the analysis are: How did the economic, social and territorial transformations affected the historical development of Villa Muñecas? What are the current manifestations of poverty in the area? What changes can be observed in the configurations of poverty?
\end{abstract}


A case study is carried out centered on the dimensions related to work and habitat and taking into consideration the historical development.

Key words: work deterioration - poverty - habitat - Villa Muñecas

\section{Introducción}

Las transformaciones socioeconómicas que tuvieron lugar en Argentina, y en los países de América Latina, en las tres últimas décadas del siglo XX provocaron la expansión e intensificación de la pobreza urbana (Arriagada, 2000; Katzman 2001; Saraví, 2004; Ziccardi, 2008). Dicho proceso se plasmó en el progresivo empobrecimiento de sectores medios y en un mayor deterioro de los sectores peor posicionados en la estructura social.

Diversos estudios dieron cuenta de la "nueva pobreza" como expresión de la caída en el nivel de ingresos de capas medias de población que luego se combinó con la precarización laboral, marcando un punto de no retorno en la mayoría de las situaciones (Kessler y Di Virgilio, 2008). ${ }^{2}$ Segmentos de población que, desde la década de 1930, habían experimentado una movilidad social ascendente por su incorporación a la incipiente industria nacional o al sector de servicios también en pleno crecimiento, sufrieron un proceso de pauperización desde mediados de los años 70, que se agravó durante la recesión de 1998-2002. A partir de 2003, en la posconvertibilidad, si bien mejoraron algunos indicadores económicos y sociales, la degradación de los ingresos y la precarización general del trabajo continuaron afectando las condiciones de estos hogares. ${ }^{3}$

La intensificación de la pobreza, por otro lado, agravó las condiciones de quienes ya tenían una participación marginal en el mercado de trabajo y vivían en las llamadas villas de emergencia -identificados como pobres de vieja data-. Se produjo una situación de competencia en el mercado de trabajo, por el cual los pobres estructurales perdieron elegibilidad y puestos tradicionalmente de sectores bajos fueron ocupados por sectores medios empobrecidos, pero más calificados (Kessler y Di Virgilio, 2008). De esta manera, los afectados por la pobreza estructural enfrentan mayores restricciones para ingresar, aunque sea de forma intermitente, al mercado de trabajo formal e incluso informal.

En ese contexto, el artículo constituye un estudio de caso donde se desenvuelven los procesos mencionados evidenciando el pasaje de un barrio obrero a un área de pobreza. Tiene la particularidad que se sitúa en Gran San Miguel de Tucumán (GSMT), la ciudad intermedia más importante del Noroeste Argentino, y sintetiza el devenir del sistema ferroviario y la actividad azucarera en la provincia.

\footnotetext{
2 Las causas principales de empobrecimiento fueron cambiando. Mientras que en la década de 1980 se debió a la conjunción de los bajos salarios, alta inflación y destrucción de pequeña industria y comercio; en los noventa fue sobre todo resultado de los elevados índices de desempleo, expansión de la precarización laboral, y una distribución del ingreso muy regresiva para los trabajadores poco calificados. Las transformaciones económicas regresivas, y el deterioro laboral que ocasionaron, llevaron a que la pobreza afectara a casi el $40 \%$ de la población de los aglomerados en 2001 . Un año después, fruto del impacto que tuvo la devaluación y la recesión económica, la pobreza abarcaba a casi el $60 \%$ de la población, entre ellos innumerables miembros de la clase media.
}

3 Kessler y Espinoza (2003) introducen el concepto de "movilidad espúrea" para referirse al proceso mediante el cual una persona puede haber ganado en jerarquía ocupacional, social -y aun en ingresos corrientes- pero la pérdida de estabilidad sin duda afecta su percepción de bienestar. 
El artículo se centra en Villa Muñecas, un barrio situado en el noroeste del GSMT cuya impronta estuvo marcada por la estación ferroviaria Muñecas y el asentamiento de trabajadores ferroviarios y azucareros. Los interrogantes que orientan la investigación son ¿Cómo incidieron las transformaciones económicas, sociales y territoriales en el devenir histórico de Villa Muñecas? ¿Cuáles son las manifestaciones actuales de la pobreza en esta área? ¿Qué cambios se observan en las configuraciones de la pobreza?

\section{Consideraciones teóricas y metodológicas}

Partimos de considerar la pobreza como una situación estructural, y no como la suma de dimensiones o aspectos parciales de privación, en la que se encuentran determinadas familias producto de su particular inserción en la estructura socioproductiva, siendo ésta la que determina la posibilidad de acceder o no, en mayor o menor medida, a determinados bienes y servicios. (Moreno, 2009)

Si bien los estudios sobre la "nueva pobreza" se refieren a aquellos sectores medios que, por el deterioro de sus ingresos, enfrentan dificultades para acceder a los bienes y servicios básicos necesarios (Minujín, 1992; Minujín y López, 1994; Beccaria y Maurizio 2005), entendemos que esta situación también se produce por condiciones laborales precarias y problemas de empleo que, en muchas ocasiones, perduran en el tiempo. Se trata, por lo general, de una población que experimentó una movilidad social ascendente durante la etapa de la industrialización sustitutiva de importaciones, y que, debido a las transformaciones económicas y sociales de las últimas tres décadas del siglo XX, sufrió un proceso regresivo sin posibilidades de retorno en la mayoría de las situaciones. En ese sentido:

[...] el empobrecimiento marcó un corte abrupto con el modelo generacional y con el modelo histórico-cultural hasta entonces vigente, signado por la expectativa de movilidad ascendente y esto otorga a la pauperización su carácter excepcional en la historia argentina moderna. (Kessler y Di Virgilio, 2008, p. 40)

Esta situación estructural de pobreza se traduce, a su vez, en carencias relacionadas con la vivienda, la salud, y la educación.

A la pobreza urbana ya identificada, a nivel espacial, con las villas de emergencia y asentamientos informales, que tuvo un gran crecimiento en el período que se estudia, se suma aquella que se expresa en los intersticios de la ciudad y cuya manifestación es un proceso de deterioro y transformación del parque habitacional existente, que incluye la lenta alteración del uso y el estado de las estructuras materiales.

Los hogares permanecen en los tradicionales barrios de clases medias $y$, si tienen suerte, mantienen en propiedad su vivienda; sin embargo, están imposibilitados de introducir mejoras, de invertir en mantenimiento e incluso se ven obligados a hacer modificaciones en los ambientes de la casa para generar pequeños espacios productivos, como talleres o pequeños comercios. (Kessler y Di Virgilio, 2008, p. 45) 
Los denominados barrios obreros -aquellos en los que una porción mayoritaria de sus residentes compartía experiencias de trabajo en los mismos establecimientos industriales, mineros, vinculados al transporte, etc.- son espacios que también atravesaron transformaciones. Muchas ciudades latinoamericanas, las grandes ciudades o ciertas capitales provinciales, experimentaron el desarrollo de estos barrios en el contexto de la industrialización por sustitución de importaciones (Katzman, 2003; Vidarte Asorey, 2009). ${ }^{4} \mathrm{Su}$ población provenía de áreas rurales y pueblos del interior que migraba en busca de un trabajo en la incipiente industria nacional o en el Estado, también en pleno crecimiento.

El proceso de desindustrialización en el marco de las políticas neoliberales produjo una des-estructuración de muchos barrios obreros. Se convirtieron en barrios de desocupados pasando del trabajo estable y la identidad laboral a la necesidad de apelar a cualquier tipo de actividad para sobrevivir.

En el presente trabajo se analizan las manifestaciones actuales de la pobreza en el caso de estudio teniendo en cuenta esta perspectiva histórica y centrándonos en las dimensiones vinculadas al trabajo y al hábitat, principalmente.

Uno de los factores principales factores que explican el fenómeno de la pobreza es el deterioro laboral. "Uno de los elementos comunes a todas las situaciones de pobreza [...] es la insuficiencia de ingresos" (Lo Vuolo, Barbeito, Pautassi y Rodríguez, 2004, p. 126), puesto que:

[...] es la variable fundamental que hace posible acceder a un consumo que permita la satisfacción socialmente aceptable de los bienes y servicios necesarios para la reproducción. El ingreso, para la mayoría de la sociedad, es producto del trabajo. Y la desocupación su expresión más negativa [...] (Hintze, 1991, p. 69)

Un trabajador sin ocupación no participa del proceso de creación de bienes y servicios y por lo tanto, queda marginado de la distribución de riqueza que surge en el proceso de producción. A su vez, aquellos que se encuentran ocupados, pueden sufrir bajos niveles salariales, condiciones precarias de empleo o bien, pueden no poseer una ocupación plena (Lindenboim, 2005).

Importa señalar que la población económicamente activa (PEA) está conformada por los ocupados y los desocupados, es decir por el "[...] conjunto de personas que [...] tiene una ocupación o que sin tenerla (por ser desocupado) está en condiciones de trabajar y la busca activamente" (Neffa, 2005, p. 73). ${ }^{5}$ Por su parte la población inactiva (PEI) abarca a los niños y jóvenes, sean o no estudiantes, a los jubilados y pensionados, amas de casa y a los que sin ser estudiantes, jubilados y amas de casa no trabajan ni buscan trabajo.

Entendemos el hábitat como el entorno donde el grupo familiar desarrolla sus actividades, lo que incluye la vivienda en sí, la infraestructura (agua potable, electri-

4 Ciudades como Buenos Aires, Córdoba, Rosario y Tucumán (Merklen, 1995).

5 Desocupado es aquel que, sin tener ocupación, la busca activamente. 
cidad, gas, desagües pluviales y cloacales, pavimento, alumbrado público, recolección de residuos, entre otros) y la accesibilidad a los equipamientos sociales (como salud, educación, recreación, cultura, comercio y sistemas de transporte y comunicaciones) (INDEC, 1990).

A nivel metodológico, para abordar las manifestaciones actuales de la pobreza en el aglomerado GSMT se utiliza el Índice de Privación Material de los Hogares (IPMH), indicador elaborado por el Instituto Nacional de Estadísticas y Censos (INDEC) sobre la base de la información del Censo de Población, Hogares y Vivienda del año 2001. El IPMH se obtiene a partir de la combinación de dos indicadores: el de condiciones habitacionales (CONDHAB) y el de capacidad económica del hogar (CAPECO).

El primero combina características de los materiales constructivos y de la infraestructura sanitaria que componen la vivienda (hogares con piso de tierra, techos sin cielorraso de chapa, fibrocemento, plástico, cartón, cańa, tabla, paja con barro, paja sola- y que carecen de inodoro con descarga de agua).

El segundo se aproxima al nivel de ingresos del hogar combinando los ańos de educación formal aprobados por los perceptores de ingresos y la cantidad total de miembros del hogar. Según el tipo de privación, distingue cuatro categorías de hogares: a) hogares sólo con privación de recursos patrimoniales; b) hogares sólo con privación de recursos corrientes; c) hogares con privación convergente -combinan carencias patrimoniales y coyunturales-; y d) hogares sin privación (Gómez, Mario y Olmos, 2003). Es decir que este indicador considera variables vinculadas a la pobreza estructural y a la pobreza coyuntural.

El IPMH se caracteriza por un elevado nivel de desagregación, y brinda la posibilidad de detectar las áreas de mayor pobreza en el conjunto de hogares carenciados, obteniendo así una medida de la intensidad del fenómeno. Esta se calcula sobre la base del peso relativo que poseen los hogares con privación convergente en el total de hogares con privación.

Para captar las manifestaciones más actuales de la pobreza se utiliza el método de las Necesidades Básicas Insatisfechas (NBI), en tanto el IPMH no se encuentra disponible en el Censo Nacional de Población, Hogares y Vivienda 2010. Éste último, a diferencia del IPMH, capta principalmente carencias vinculadas a la pobreza estructural como condiciones de vivienda deficitaria y bajo nivel educativo. ${ }^{6}$

6 Cabe señalar que el criterio de las NBI tiene serias limitaciones, Un primer problema se vincula con los indicadores considerados, ya que los mismos no contemplan la realidad de aquellos sectores de la sociedad que, debido a un proceso de deterioro de su poder adquisitivo, han caído en situación de pobreza, aunque cuentan con una vivienda con infraestructura adecuada, o nivel educativo y asistencia escolar aceptable. De esa forma, la pobreza coyuntural no es percibida por esta metodología. Por otra parte, los indicadores seleccionados poseen un alcance restringido puesto que hacen referencia a las características de la vivienda, la situación escolar o la carga familiar por ingreso, mientras que no se tiene en cuenta otras necesidades esenciales como ser la alimentación, la salud o la vestimenta. Otra limitación que presenta este método es la subestimación de la pobreza crónica urbana. Al considerar indicadores que reflejan niveles de privación muy críticos, se tiende a excluir un número importante de pobres urbanos. Los indicadores de vivienda y educativo excluyen situaciones de viviendas con 
En cuanto a la situación laboral, se trabajó con las tasas de actividad, empleo y desocupación, ${ }^{7}$ y se tuvo en cuenta a quienes están afectados por el empleo informal, es decir, quienes no perciben aportes para la jubilación. La descripción del proceso de surgimiento, consolidación y empobrecimiento de Villa Muñecas se realiza a partir de la revisión bibliográfica mientras que la descripción de las manifestaciones actuales de la pobreza se realiza a partir del análisis de entrevistas semiestructuradas a una muestra aleatoria de hogares y datos censales del 2001 a nivel de radios (los que se corresponden con el área de estudio).

\section{El crecimiento del Gran San Miguel de Tucumán}

El aglomerado GSMT comprende un conjunto de localidades distribuidas entre cinco departamentos de la provincia, incluyendo distintos municipios y comunas rurales, cuyo núcleo es la capital provincial (Ver Figura 1). Su población alcanzaba en el año 2010, según el Instituto Nacional de Estadística y Censos (INDEC), los 839.904 habitantes.

Si bien es la ciudad intermedia más importante del Norte Grande Argentino, ${ }^{8:}$ en términos demográficos y por las funciones que cumple como centro comercial, financiero y cultural de la región, su población enfrenta un acentuado deterioro social. En el año 2001 los datos censales reflejaban que aproximadamente la mitad de los hogares del aglomerado presentaban algún tipo de privación y, dentro de ese conjunto, los hogares con privación patrimonial y de ingresos eran los predominantes (Longhi, 2012).

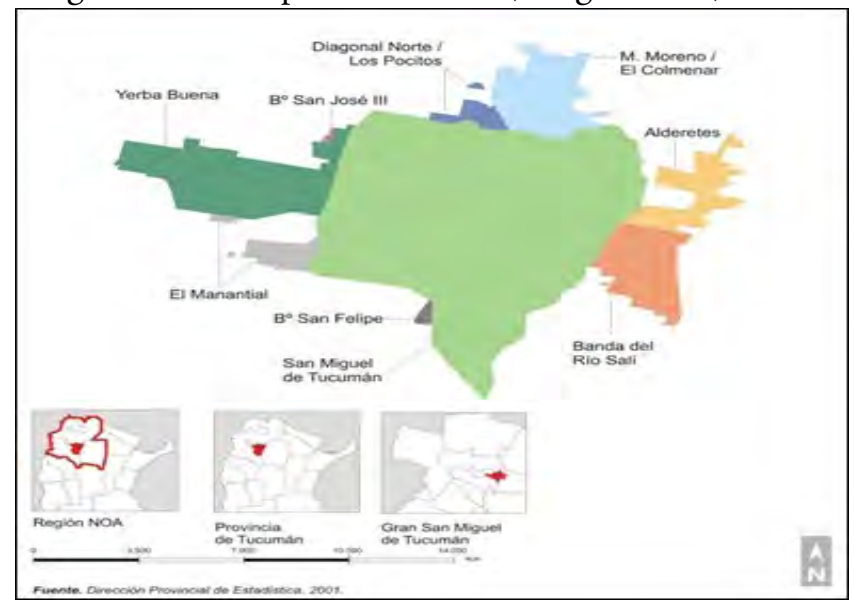

Figura 1. Gran San Miguel de Tucumán

Elaboración: Laboratorio de Cartografía Digital.

Instituto Superior de Estudios Sociales. CONICET - UNT

severas carencias o situaciones educativas no satisfactorias, es claro que esta metodología subvalúa la pobreza existente.

7 La tasa de actividad expresa el peso de la PEA en la población total. Por su parte la tasa de empleo surge del cociente entre los ocupados y la población total, mientras que la tasa de desocupación expresa el porcentaje de la PEA que está desocupada.

8 Región conformada por nueve provincias del norte argentino: Catamarca, Jujuy, Salta, Santiago del estero, Tucumán, Chaco, Corrientes, Formosa y Misiones. 


\subsection{Incidencia del desarrollo azucarero y el ferrocarril en el crecimiento y es- tructuración del Gran San Miguel de Tucumán}

El crecimiento y desarrollo de SMT, y con posterioridad del aglomerado, estuvo principalmente ligado al devenir de la agroindustria azucarera. Desde fines del siglo XIX hubo un proceso de expansión y predominio de la producción azucarera en la estructura productiva tucumana, transformándose en la principal actividad económica en la provincia.

Un acontecimiento trascendental que propició la modernización de dicha actividad fue la llegada del ferrocarril a la provincia en el año 1876. Este posibilitó la producción a mayor escala, en tanto viabilizó la tecnificación de los ingenios, y ubicó a Tucumán entre los principales productores de azúcar del país (Schleh, 1921; Ferrari, 2007). ${ }^{9}$

Este factor de desarrollo de la industria azucarera también jugó un rol central en el proceso de urbanización de SMT. La red ferroviaria fue el cimiento de la apropiación del territorio mediato e inmediato de la ciudad (Sosa Paz, 2006). El ferrocarril animó y estructuró buena parte de los núcleos que ya existían en las cercanías de la ciudad y los vinculó con esta. ${ }^{10}$

La estructura ferroviaria en la ciudad estaba formada por cuatro estaciones centrales localizadas en los bordes del área urbana que se construyeron entre los años 1876 y 1896 (Ver Figura 2). Al interior del cinturón de hierro, que se erigió a partir de dichas estaciones, circulaban los tranvías que conectaban las áreas más importantes de la ciudad.

Se construyeron además ocho estaciones en las inmediaciones de la ciudad, las cuales conectaron distintos núcleos poblacionales surgidos en torno a ingenios o cascos de quintas y a villas veraniegas (como en el caso de Marcos Paz). ${ }^{11}$ Dichas estaciones se denominaban: Alderetes, Muñecas, Yerba Buena, 24 de Setiembre, Mate de Luna, Manantial, San Pablo y Tafí Viejo -esta última al norte, con sus importantes talleres ferroviarios de envergadura nacional. ${ }^{12}$ En torno a estas estaciones también se generaron pequeños poblados (asentamientos de población), como es el caso de Villa Muñecas (Ver Figura 2).

9 La principal idea que dominó la construcción de cualquier línea ferroviaria fue el aspecto económico, es decir, la existencia de una producción agrícola, ganadera o mineral o la posibilidad de algún tipo de producción de la región por donde atravesarían los rieles, cuyo transporte generase divisas para la empresa que lo explotara o la existencia de materias primas explotables por parte de la empresa que explotaba el ferrocarril. En el caso de Tucumán y del noroeste argentino éste llegó, fundamentalmente, por la producción de la caña de azúcar y el transporte de maquinarias para los ingenios azucareros (Ferrari, 2007).

10 La ciudad que durante casi 300 años no había cambiado significativamente, a partir de este momento lo hace radicalmente. Junto a la llegada del ferrocarril se instalan diversos servicios (agua potable, electricidad, alcantarillado, teléfono, telégrafo, tranvía, etc); bulevares; y calles y veredas más anchas. Esto tiene que ver con la introducción de las ideas liberales y la noción de progreso.

11 De igual manera, la red ferroviaria permitió que no quedara ningún paraje que distara a más de 45- 50 kilómetros de alguna línea, salvo algunos puntos de los departamentos de Trancas y Burruyacu. El ferrocarril se convirtió en el medio de transporte no sólo de la materia prima y de los insumos sino también de la mano de obra en sus movimientos estacionales (Paolasso, 2004).

12 Tafí Viejo era un incipiente pueblo veraniego ubicado a 15 km de SMT. La construcción de los talleres ferroviarios y su inauguración en el año 1910 cambiaron el perfil del pueblo. 


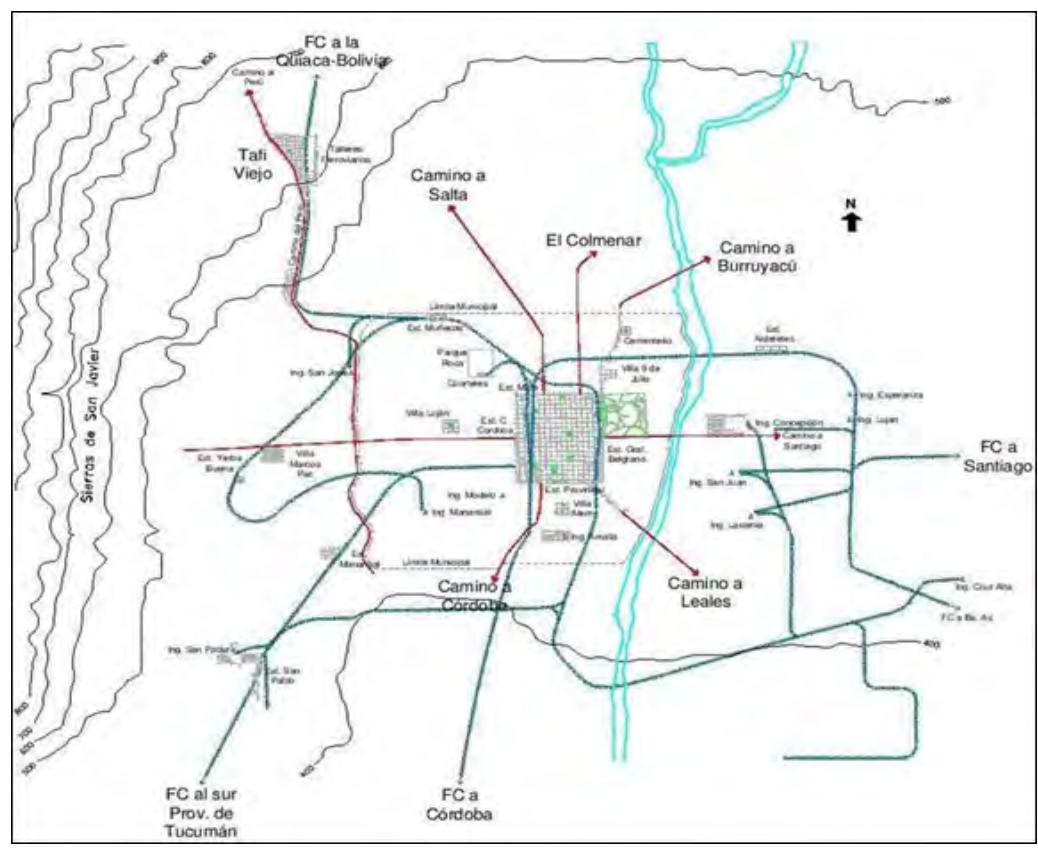

\section{Figura 2. San Miguel de Tucumán y sus alrededores en 1920}

Fuente: Sosa Paz, 2006 Elaboración: Sosa Paz, 2006

El funcionamiento de 11 ingenios azucareros en los alrededores de la ciudad, junto a las posibilidades de traslado abiertas por el ferrocarril, incidieron en su crecimiento. Estos actuaron como polo de atracción no solo de la población criolla sino también de extranjeros que se radicaron en sus inmediaciones como técnicos y comerciantes (Zerda de Cainzo, 2002). Los núcleos poblacionales situados al este del río Salí, vecinos a SMT, fueron las más afectadas por este proceso. Es lo que ocurrió en Lastenia, Banda del Río Salí, Ingenio San Juan y Alderetes, lugares donde la población golondrina atraída por el trabajo, poco a poco, se fue haciendo estable. Este fenómeno perduró aun cuando algunos de los ingenios posteriormente desaparecieron (Zerda de Cainzo, 2002). No obstante, pese al desarrollo e importancia que fue adquiriendo la actividad azucarera, ésta atravesó una serie de momentos críticos ligados a una limitación estructural: su orientación al mercado interno. ${ }^{13}$ Las dificultades para dirigir la producción al mercado internacional, las fluctuaciones de precios y los conflictos con el sector cańero por el precio de la materia prima marcaron su devenir (Lenis, 2011).

La crisis de mayor envergadura acaeció durante la década de 1960. Esta dejó como saldo el cierre de 11 ingenios azucareros, de los 27 existentes en Tucumán, provocando un pronunciado deterioro laboral en la provincia. Alrededor de 50.000 obreros y empleados quedaron sin trabajo junto a la exclusión de cerca de 11.000 pequeños cañeros. La desocupación a partir del año 1967 afectó al 10\% o más de la Población Económicamente Activa (PEA) de la capital tucumana (Osatinsky y Paolasso, 2007).

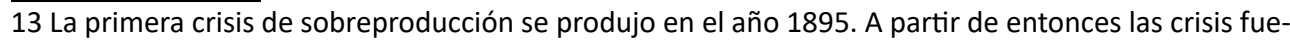
ron recurrentes debido a la saturación del mercado interno o a los períodos de escasez por efecto del clima o de las plagas que afectaron a los cañaverales. 
Como resultado de esta crisis, la provincia de Tucumán sufrió un retroceso demográfico junto a un pronunciado proceso migratorio hacia el aglomerado capitalino. ${ }^{14}$ Los flujos de migrantes no sólo se dirigieron a SMT, se verificó también el crecimiento de ciertas áreas contiguas. Este proceso provocó que en 1970 -si se consideraba el aglomerado- se evidenciara la consolidación del proceso de concentración de la población, ya que por entonces aproximadamente la mitad de la población de la provincia residía en la capital y sus alrededores (Osatinsky y Paolasso, 2007). En las décadas siguientes, la mecanización de la cosecha y el retroceso gradual del peso de la industria azucarera, que pese a ello siguió siendo la de mayor importancia en la economía provincial, continuaron afectando a las poblaciones vinculadas con este sector. El crecimiento de otras actividades agropecuarias no logró contrarrestar o revertir las consecuencias de la crisis del sector azucarero (Osatinsky y Paolasso, 2012). ${ }^{15}$ El GSMT continuó recibiendo familias migrantes afectadas por este declive, aunque en menor medida que en ańos anteriores.

\subsection{La pobreza y su distribución en el GSMT}

El desarrollo de la agroindustria azucarera, si bien le permitió a GSMT convertirse en una de las ciudades más dinámicas del interior del país, también es uno de los factores centrales que explican las formas y magnitud de la urbanización de la pobreza. $\mathrm{Ni}$ en los períodos de auge -mucho menos en los críticos- la economía sustentada sobre el azúcar pudo sostener a la población provincial. La gran crisis azucarera, acaecida durante la década de 1960, acentuó esta situación y produjo un proceso de migración desde las áreas afectadas por el cierre de once ingenios al GSMT, entre otros destinos menos importantes (Bolsi y Ortiz D’Arterio, 2001; Osatinsky y Paolasso, 2007), expandiendo los problemas de empleo y de pobreza preexistentes en el referido núcleo urbano.

Las políticas neoliberales implementadas desde la dictadura de 1976 y con mayor profundidad en la década de los noventa -que en Tucumán se manifiestan más tempranamente con el cierre de los ingenios-, provocaron un agravamiento de la situación (Osatinsky, 2009).

El cálculo de la intensidad del IPMH, como se observa en la Figura 3, permite analizar la distribución de la pobreza y los elevados niveles que presenta el aglomerado. En la periferia del aglomerado prevalece un cordón de pobreza crítica, junto a la presencia de algunas islas, con umbrales que superan el 50\% de intensidad. Por otro lado, si bien los niveles mejoran en los sectores más próximos al área central, éstos igualmente siguen concentrando una significativa presencia de hogares con severas privaciones. Finalmente, la mayor cantidad de hogares sin privaciones se concentran en el área central y en el sector oeste del aglomerado.

14 Entre 200.000 y 250.000 tucumanos - cerca del 30\% de la población-emigraron de la provincia con motivo de la crisis. A excepción de la capital provincial, que se constituyó en receptora de población, y del departamento Tafí, todos los departamentos registraron un descenso poblacional en este período 1960-1970 (Osatinsky y Paolasso, 2007).

15 A medida que la industria azucarera retrocedía la actividad citrícola cobraba mayor peso. Desde fines de la década de 1960 numerosos productores reemplazaron el cultivo de caña por la producción de limones. En la década de 1990 se sumaron como causales de expansión de la producción limonera el incremento de los precios internacionales y de la demanda tanto de la fruta fresca como de los derivados industriales. Si bien la expansión de la industria citrícola pudo atenuar el impacto negativo que ocasionaron los problemas del sector azucarero de ningún modo pudo revertirlos (Osatinsky y Paolasso, 2012). 


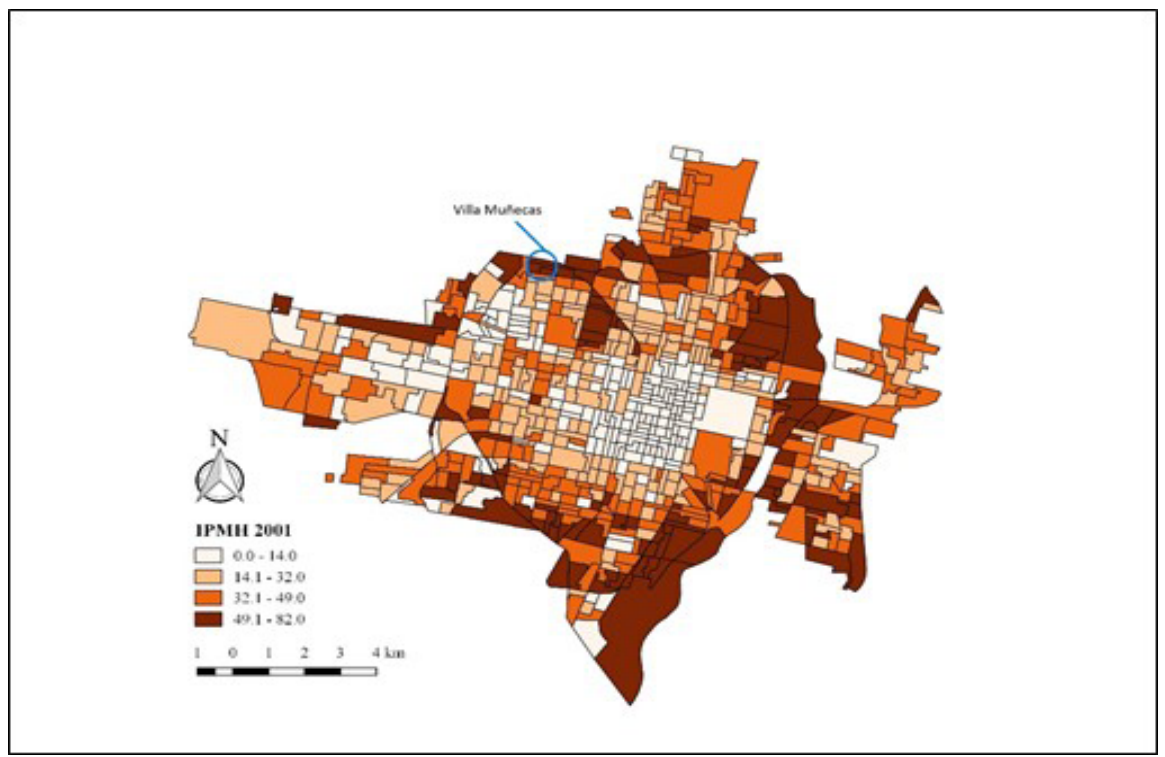

Figura 3. Gran San Miguel de Tucumán, Intensidad IPMH 2001

Fuente: Censo Nacional de Población, Hogares y Viviendas 2001

Debido a que el IPMH no puede calcularse para el año 2010, se utilizó el método de las NBI que, como ya se explicó, mide carencias estructurales y posee limitaciones importantes. Según este método, en 2010 se produjo una reducción del $5 \%$ en los hogares con al menos una necesidad básica insatisfecha -pasa del 16\% al 11\%-. La Figura 4 muestra que la pobreza tenía una distribución similar a la existente en 2001.

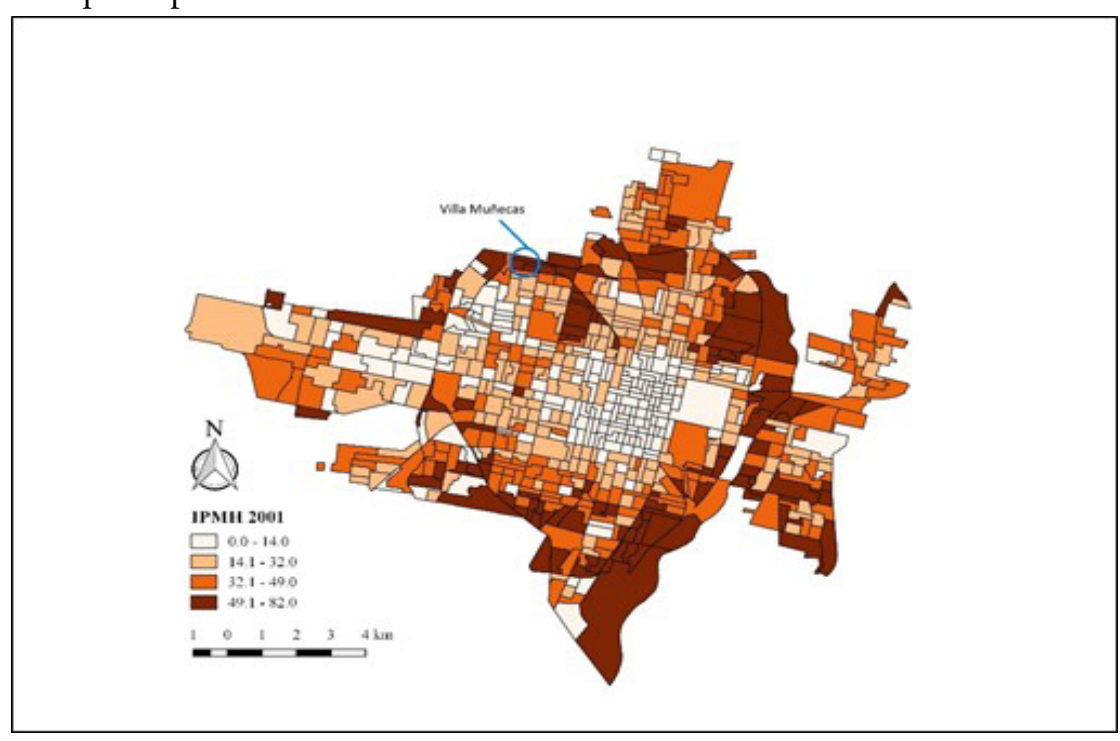

Figura 4. Gran San Miguel de Tucumán, NBI 2010

Fuente: Censo Nacional de Población, Hogares y Viviendas 2010 
Villa Muñecas, situada al noroeste del GSMT como ya se expuso, constituye un área de la ciudad que agrupa a población empobrecida y en condiciones de pobreza estructural.

\section{Villa Muńecas en este contexto: historia y espacialidad}

Villa Muñecas fue una de las áreas que comenzó a poblarse en las márgenes de la ciudad en el sector noroeste a partir de la fundación de la estación ferroviaria Muñecas a comienzos del siglo XX (Ver Figura 2). Atrajo las primeras corrientes migratorias, desde las zonas rurales a las ciudades, que fueron poblando los alrededores de los ingenios y las estaciones de ferrocarril. Con posterioridad continuó recibiendo población, experimentando distintas ampliaciones que en la actualidad reflejan la heterogeneidad de las trayectorias de su población.

La fundación de la estación ferroviaria Muñecas a fines del siglo XIX (1898, según entrevistas a informantes clave) constituyó el hecho fundante de Villa Muñecas (Centeno, 2013). Dicha estación fue emplazada sobre el tendido del ferrocarril Central Norte que se extiende desde la ciudad capital hasta la ciudad de Tafí Viejo (Ver Figura 2). Cumplía la función de terminal intermedia para la carga y descarga de animales. "Llegó a contar con 10 vías para el cambio de formaciones. Tenía el brete, lugar para alimentar a los animales que llegaban en los vagones y que debían seguir viaje al norte, o bien, pasar a los camiones para continuar camino hacia las bocas de consumo" (La Gaceta, $18 / 10 / 2011)$.

Su instalación propició el poblamiento estable de este sector alejado de la ciudad. Con anterioridad, la zona se caracterizaba por la presencia de quintas dispersas de cítricos y el incipiente cultivo de la cańa de azúcar impulsado por el Ingenio San José, ubicado en las cercanías. El único poblamiento consistía en casas dispersas pertenecientes a los cuidadores de las fincas (Centeno, 2013).

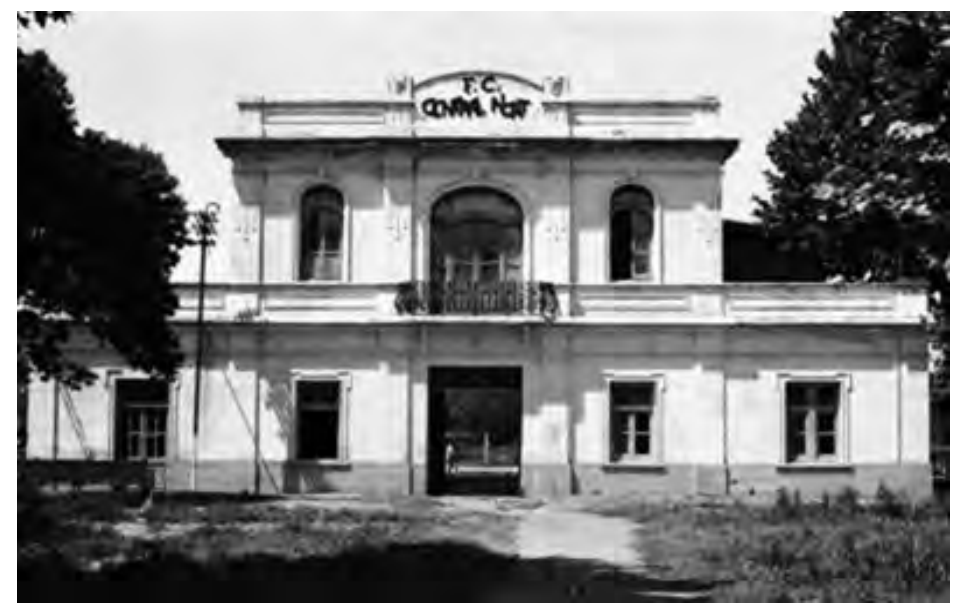

Figura 5. Estación Muñecas en funcionamiento

Fuente: www.erf.com.ar 
La población de Villa Muñecas, desde la fundación de dicha estación, se incrementó de manera notable en un breve período. En forma progresiva las familias se fueron asentando.

Dicha población se componía principalmente de peones que trabajaban en la carga y descarga de ganado de los trenes que llegaban a la estación, obreros ferroviarios (que prestaban tareas en el servicio de transporte como en los talleres de reparación y mantenimiento de Tafí Viejo) y trabajadores de la caña de azúcar. La zona era conocida como Villa "El Charqui" porque cuando morían o se quebraban animales (en las tareas de carga/descarga) los faenaban y repartían entre los vecinos para hacer charqui, forma de preparación de la carne para su conservación. (Centeno, 2013)

El ferrocarril desempeñó un papel fundamental no sólo en las oportunidades laborales de los vecinos, sino también como medio de transporte de carga y pasajeros. Posibilitaba, de esta manera, la participación en la vida de la ciudad -la cultura, educación, producción y circulación de bienes- y el desarrollo de relaciones sociales al poner en contacto a personas de diferentes zonas (Bertotti, 2006). El relato de uno de los vecinos más antiguos manifiesta esta función:

[...] Usaba el tren de pasajeros. ¡Claro! Le cuento, había "el salteño", que le decíamos cuando venía de Salta, cuando venía de allá, de Buenos Aires, "el tucumano", le decíamos. Le cuento, de aquí había un local, le decían, corría desde el Bajo nomás -la terminal vieja- a Tafí Viejo. Y había uno que pasaba al Cadillal $y$ de ahi volvía. Habia uno, cuando podiamos viajar, había uno a las 6 de la mañana que era el obrero. Iba a Tafí Viejo a los talleres. Después teníamos uno a las 8, a las 9 e iban hasta Tafí Viejo y volvían a la terminal. Al Bajo, que le decíamos Central Norte. (Extraído de Bertotti, 2006)

Otro factor de gran relevancia en el crecimiento de Villa Muñecas fue la construcción a fines de 1890 de los Depósitos de Aguas Corrientes perteneciente Obras Sanitarias de la Nación (en la zona en que hoy se emplaza el barrio Aguas Corrientes), la cual demandó una considerable cantidad de obreros. Ésta dio lugar a la primera planta potabilizadora de agua de la ciudad (Centeno, 2013).

En la década de 1950 Villa Muñecas se expandió a partir de loteos legales que realizaron los dueños de las quintas aledañas. Parte de los que ya se encontraban viviendo en la zona accedieron a la compra de estos lotes junto a la llegada de nuevos pobladores. Se trataba principalmente de empleados del ferrocarril y trabajadores azucareros.

La crisis azucarera de la década del sesenta, y el desplazamiento poblacional de los trabajadores afectados por el cierre de los ingenios, produjo nuevas ocupaciones en la zona. Las familias, en forma progresiva, fueron asentándose a orillas del Canal Norte originándose el denominado asentamiento Villa Muñecas Norte, que continuó ampliándose en las siguientes décadas. La distinción respecto al resto del barrio surge por las distintas trayectorias de sus pobladores. Hasta la actualidad son los hogares que tienen inserciones laborales más precarias y en los que persiste la precariedad habitacional. 
El Operativo Independencia, y con posterioridad la última dictadura militar, marcaron Villa Muñecas porque en un pozo de la zona llamado por los vecinos "pozo de Vargas", que proveía de agua al ferrocarril, se realizaron múltiples inhumaciones clandestinas entre los ańos 1975 y 1977. Dicho pozo está ubicado al costado de las vías, al interior de una finca en la que se cultivaba caña y luego citrus. (Bertotti, 2006)

Los vecinos del barrio asistían aterrados a las caravanas de vehículos que por las noches llegaban hasta ese lugar, para que los "ocultadores de cadáveres" arrojaran los cuerpos al pozo. Esta producción singular de enterramientos clandestinos, pero a la vista de todos, trajo aparejados efectos sociales perturbadores para el desarrollo de la interacción cotidiana. (Bertotti, 2009, p. 5)

El desmantelamiento progresivo del sistema ferroviario que se inicia con la dictadura pero que fue llevado a fondo durante la década del '90, implicó el cierre de ramales y estaciones junto al despido de miles de trabajadores ferroviarios. Villa Muñecas fue claramente afectada por este proceso en lo que respecta tanto al despido de los vecinos que eran trabajadores ferroviarios como el deterioro de la zona por el cierre de la Estación y del servicio (Ver Figura 6).

En entrevistas realizadas por Bertotti (2006) se reflejan los efectos sobre la población:

[...] Cuando dejó de funcionar el tren cambió el barrio... Y bastante, porque han empezado algunos a irse a trabajar a otros lados y hasta los negocios... No ha visto que antes corría, trabajaban en el ferrocarril, andaban... todos eran ferroviarios y tenían su plata. Había muchos ferroviarios... Sí, muy buenos. El otro hermano mío, el finado Daniel, era ferroviario. Trabajaba, no trabajaba en el taller, trabajaba en las vías. Arreglando las vías... Sí. Y bueno, ha mermado...

Bueno, el ferrocarril una vez que ha dejado de funcionar ha quedado aquí mucha gente sin trabajo eh... ahí al frente, donde está ese barrio, no existía el barrio, era una playa donde estacionaban los vagones, había una playa de almacenamiento, eh..., trabajaban casi todos los de habitantes de este barrio ahí. Entonces al dejar de funcionar... Nosotros de acá, por ejemplo, para ir a la escuela lo utilizábamos al tren, yo iba a la escuela de comercio, así que subía al tren acá a la una, a la una y media y a las dos menos cuarto ya estaba bajándome allá en la calle Muñecas, que era la próxima parada, y me quedaba muy cerca para... para ir a la escuela... Y había gente de Tafí Viejo que iba... también, o gente que iba trabajar porque eran horarios claves. Eran horarios claves, y además que era muy barato. Y muy barato el pasaje, el tiempo[...]. (Bertotti, 2006) 


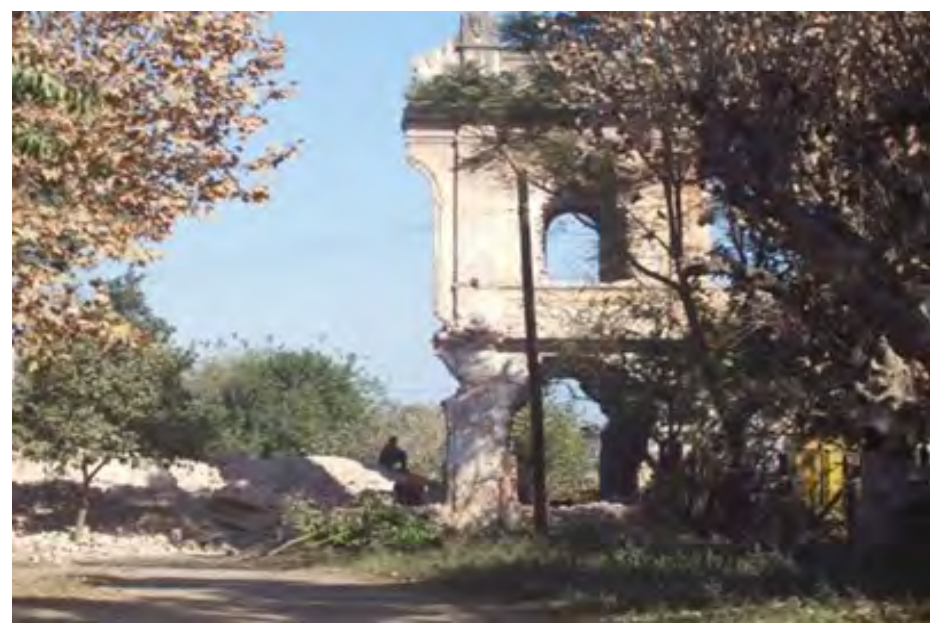

\section{Figura 6. Estación Muñecas en la actualidad.}

Fuente: www.erf.com.ar

Es en este período que se producen nuevas ocupaciones en Villa Muñecas Norte principalmente sobre los terrenos en desuso del ferrocarril y en los espacios que quedaban vacíos del canal.

Durante la primera mitad de la década de 1990 se instalan también un grupo de trabajadores del ingenio Concepción. Éstos pertenecían a la Colonia Los Pocitos y fueron trasladados por el Ingenio con la promesa de que los terrenos iban a ser de ellos. Este sector se conoce como La Tira. Sin embargo, hasta la actualidad las familias no tienen las escrituras de los mismos (Boldrini, 2012).

Isla, Lacarrieu y Henry (1999) describían algunas características de estas nuevas ocupaciones en su etapa inicial:

Un grupo de familias distribuye sus viviendas en forma de hilera entre la vía del tren y el bañado, aprovechan la franja de tierra del terraplén para instalar sus casillas, con gallineros, hornos de pan, corrales para chanchos, palenques para caballos y espacio para la chatarra que recogen diariamente. Combinan actividades de venta ambulante, cirujeo, con una producción doméstica diversificada. La mayoría de estas viviendas son levantadas con maderas, chapas, botellas y cartón, linderas y dando sus espaldas, a las vías del ferrocarril o del Canal Oeste. No disponen de luz eléctrica, agua, gas, ni retrete en la vivienda". (Isla, 1999, p. 248)

En la actualidad estos vecinos ya lograron acceder a ciertos servicios básicos como electricidad y agua corriente. También en muchos casos llevaron a cabo mejoras en las viviendas, por lo general la construcción de alguna pieza de material. 


\section{Villa Muñecas en la actualidad}

El desmantelamiento del sistema ferroviario y el cierre de la Estación Muńecas en la década de 1990 afectaron a toda la población del barrio, sin embargo, el deterioro social se expresó de distintas maneras. Las trayectorias laborales de sus pobladores permiten entender, en gran parte, estas diferencias.

\section{1. ¿Qué pasó con el barrio obrero?}

Tratándose del área que tuvo mayor prosperidad, por la vinculación de su población con el empleo en el sistema ferroviario ${ }^{16} \mathrm{y}$ en la agroindustria azucarera en una época de crecimiento, las condiciones actuales reflejan el deterioro social resultado de la crisis de ambas actividades.

La privatización y posterior desmantelamiento del sistema ferroviario en las décadas de 1980 y 1990 provocaron despidos y retiros voluntarios masivos. ${ }^{17} \mathrm{En} \mathrm{Tu}$ cumán se desactivaron todas las líneas ferroviarias, a excepción del tren de pasajeros con destino a ciudad de Buenos Aires que hace este recorrido dos veces a la semana, y el Belgrano Cargas para el transporte de las producciones regionales que funciona de manera intermitente. ${ }^{18}$ En consonancia se cerraron estaciones y predios ferroviarios, siendo la única en funcionamiento la Estación Mitre. Los Talleres de Tafí Viejo fueron sometidos también a un proceso de desguace, ${ }^{19}$ quedando cerca de 100 trabajadores en los años de la posconvertibilidad. ${ }^{20}$ Estos realizan diversas tareas sobreponiéndose a la falta de inversión estatal que es lo que permitiría una reactivación o recuperación de la actividad industrial de la planta.

Si bien, por falta de datos, no se puede medir el impacto efectivo sobre la población de Villa Muñecas, esta política marcó un punto de inflexión en relación a las trayectorias laborales.

Afectados por un proceso de empobrecimiento, que se refleja principalmente en los indicadores laborales, conservan las condiciones habitacionales adquiridas en el período anterior, aunque no sin dificultades. Están imposibilitados de introducir mejoras, de

16 Los trabajadores ferroviarios tenían condiciones de trabajo y protección social superiores al resto de los gremios. Estas mejoras sustantivas se explican, en buena medida, por el carácter estratégico de la actividad ferroviaria: garantizaba la corriente de exportaciones de las que el país no podía prescindir, especialmente en términos económicos (Bergesio y Golovanevsky, 2010).

17 Entre 1985 y 1998 el empleo en las empresas ferroviarias se redujo un 85\% aproximadamente (Bergesio, Golovanevsky y Marcoleri, 2009).

18 El Belgrano Cargas circula por una red troncal centenaria de 7.347 kilómetros, que enlaza 14 provincias del norte argentino, con llegada a Chile y Bolivia. Sin embargo, por el deterioro en su mantenimiento tiene una capacidad muy limitada y no funciona de forma programada.

19 En la década de 1950 este predio llegó a albergar 5500 trabajadores. En 1975 el número de trabajadores se redujo a 3000. En 1980, cuando Roberto Eduardo Viola ordenó cerrarlos, quedaban 1700. En 1984 Raúl Alfonsín los reabrió, y durante los '90 el plantel fue disminuyendo. Ver http://www. pagina12.com.ar/diario/cultura/7-50815.html [Consultado el 9/10/2013].

20 Hasta mayo del año 2013 eran 110 los trabajadores en planta. Ver http://www.lagaceta.com.ar/ nota/545699/politica/talleres-ferroviarios-tafi-viejo-pasan-orbita-belgrano-cargas.html [Consultado el 9/10/2013]. 
invertir en mantenimiento e incluso se ven obligados a hacer modificaciones en los ambientes de la casa para generar pequeños espacios productivos, como talleres o pequeños comercios (Kessler, 20008).

A nivel de las condiciones habitacionales, el $85,5 \%$ de los hogares reside en viviendas que reúnen características adecuadas (de acuerdo a indicadores definidos por el CNPHyV 2001), mientras que el 8,6\% reúne alguna condición deficitaria ${ }^{21}$ y sólo el 4,5 vive en casillas (Ver Anexo Tabla 1).

Sobre los servicios e infraestructura urbanos, las viviendas disponen casi en su totalidad de baños instalados $(94,4 \%)$, el $89,4 \%$ tiene gas natural y acceso a la red cloacal (Ver Anexo Tabla 1).

Más que en las condiciones habitacionales, el impacto de las transformaciones económicas regresivas se percibe en el deterioro laboral que experimentó la población del barrio. La desocupación en el barrio obrero afectaba en 2001 a casi el $40 \%$ de su población activa (Tabla 1), mientras que la tasa de empleo se ubicaba por debajo del $35 \% .{ }^{22}$ En cuanto al empleo informal, el 33\% de los ocupados del barrio obrero no percibía aportes jubilatorios por la ocupación que realizaba en aquel año.

Tabla 1. Tasas de actividad, empleo y desocupación en Villa Muñecas, 2001

\begin{tabular}{|l|c|c|}
\hline & Barrio obrero & Asentamiento \\
\hline Tasa de actividad & 56,4 & 62,1 \\
\hline Tasa de empleo & 34,4 & 30,9 \\
\hline Tasa de desocupación & 38,9 & 50,1 \\
\hline
\end{tabular}

Fuente: Elaboración propia sobre la base de Centeno, 2011: 141

y Censo Nacional de Población, Hogares y Viviendas 2001

El deterioro laboral y la precariedad en relación al hábitat afectan de un modo más significativo a los habitantes de Villa Muñecas Norte, como se analiza a continuación.

\subsection{Villa Muńecas asentamiento}

Como describieran Isla et al. (1999) las condiciones habitacionales en Villa Muñecas Norte son deficitarias. Si bien se registran avances, resultado de la acción de los vecinos que

21 Según el CNPHyV 2001 este tipo de casas que presenta al menos una de las siguientes condiciones deficitarias: tiene piso de tierra o ladrillo suelto u otro material (no tiene piso de cerámica, baldosa, mosaico, mármol, madera, alfombra, cemento o ladrillo fijo); o no tiene provisión de agua por cañería dentro de la vivienda o no dispone de inodoro con descarga de agua.

22 Cabe destacar que el Censo del 2001 tuvo demasiadas dificultades durante su realización por lo que probablemente la tasa de desocupación, sin dejar de ser muy elevada, tenía una valor menor, mientras que la tasa de empleo probablemente era un poco mayor a lo que señalaba la información censal. Sucede que, en relación al censo de aquel año, “...las tareas de preparación se vieron perturbadas por la negativa del gremio docente a continuar apoyándolas lo que se extendió hasta el relevamiento propiamente tal, razón por la cual fue necesario apelar a empleados y funcionarios estatales y otras personas sin entrenamiento alguno" (Lindenboim, 2007, p.320). De esa forma, tal vez se sobreestimó la tasa de desocupación (véase Lindenboim, 2007). 
presionaron para lograr la intervención del Estado, esta dimensión constituye un aspecto estructural de las situaciones de privación. Para caracterizar los aspectos vinculados al hábitat y dar cuenta del acceso a la infraestructura y servicios urbanos, a la vivienda y el suelo urbano, se utilizan datos del Censo Nacional de Población, Hogares y Vivienda del año 2001 y de entrevistas semiestructuradas realizadas a un conjunto de hogares en el año 2011.

En lo que respecta a los servicios, según los datos censales del año 2001, el barrio no disponía de red cloacal, el $21 \%$ de las viviendas no tenía alumbrado público y el $38,3 \%$ no contaba con recolección de residuos (Ver Anexo Tabla 2). Diez años después la situación en lo que respecta a la instalación de la red cloacal prácticamente no se modificó, sólo el $2,5 \%$ de los hogares entrevistados tenía inodoro con descarga de agua a red cloacal.

La totalidad del asentamiento en el año 2001 presentaba acceso a la red eléctrica y de agua corriente y accesibilidad al transporte público (Ver Anexo Tabla 2). No obstante, en relación a la provisión de agua el Centro de Atención Primaria de la Salud (CAPS) de la zona tenía relevado en el año 2009 que el 19,9\% poseía como única conexión un grifo fuera de la vivienda y el 7,5\% extraía el agua de un surtidor público (Ver Anexo Tabla 3).

Las calles, hasta la actualidad, no están pavimentadas, lo que dificulta la accesibilidad de los medios de transporte y de los vehículos a la zona. ${ }^{23}$ A esto debemos sumarle la existencia de sectores del asentamiento con tramas urbanas muy irregulares, es decir que no están amanzanados sino organizados a partir de intrincados pasillos, donde por lo general no pueden pasar vehículos.

La situación de precariedad habitacional afectaba en el año 2001 al 56,3\% de los hogares (Ver Anexo Tabla 4). El 26,7\% de éstos tenía alguna carencia en la vivienda, relacionada con el material de los pisos, disposición de excretas o agua, y el 30\% residía en casillas y ranchos.

Los hogares que se encuentran en situación de informalidad, es decir no poseen la titularidad de los terrenos, representan el 57,3\% (Ver Anexo Tabla 5). Hay que tener en cuenta que esta variable suele presentar un subregistro, ya que los hogares, por miedo a acciones futuras por parte del Estado, no declaran su situación. ${ }^{24}$ De los hogares entrevistados en el trabajo de campo en el año 2011, el 95\% se encontraba en esta condición.

Sobre la situación educativa el $7 \%$ de los jefes/as de hogar era analfabeto y el $27 \%$ tenía primaria incompleta. El 40,4\% terminó la escuela primaria y sólo el 6,9\% presentaba estudios secundarios (Ver Anexo Tabla 6).

En cuanto a la situación laboral, en 2001 el porcentaje de población que conformaba la PEA era del $62 \%$ (Ver Tabla 1), 58\% varones y $42 \%$ de mujeres (Ver Anexo Tabla 7). Solamente el $31 \%$ de la población de 14 años o más en condiciones de trabajar tenía empleo, mientras que la desocupación afectaba al 50\% de la PEA (Ver Tabla 1).

23 En el resto del barrio el trazado y la transitabilidad de las calles es de mayor calidad.

24 Por la característica propia de la residencia en villas o asentamientos, si éstos no atravesaron un proceso de regularización, la condición de propietario sólo incluye la vivienda (y no el terreno), lo que implica una situación precaria de estabilidad residencial más allá de la forma de ocupación declarada. 
Entre los ocupados predominaba notoriamente los asalariados $(70,6 \%)$ mientras que el resto, casi en su totalidad, eran trabajadores por cuenta propia (Ver Anexo Tabla 8). La mayoría desempeñaba actividades de tipo operativas $(55,8 \%)$ y no calificadas $(30,8 \%)$ (Ver Anexo Tabla 9). Sólo al 32,4\% le descontaban o realizaban aportes jubilatorios, lo que refleja que el empleo "en negro" afectaba a la mayor parte de los asalariados y ocupados. Cabe señalar que el porcentaje de empleo informal duplicaba al que tenía la zona del barrio obrero.

Diez años más tarde, la información recabada en las entrevistas semiestructuradas a los hogares refleja que la mayoría de la población de Villa Muñecas Norte continúa siendo afectada por inserciones laborales precarias e informales. ${ }^{25}$

Los asalariados en Villa Muñecas Norte representan el 48,7\% de la población económicamente activa, siendo los varones trabajadores de la construcción y azucareros, principalmente, y las mujeres empleadas domésticas (Ver Tabla 2).

Los cuentapropistas representan el 17,9\% de la PEA de Villa Muñecas Norte, entre los que encontramos changarines y trabajadores de oficio. En el caso de las mujeres se ocupan en actividades vinculadas con la preparación y venta de comida, comestibles, cosméticos y ropa en la propia casa o en el barrio.

El 63\% de los asalariados no está registrado mientras que la totalidad de los cuentapropistas están afectados por el empleo informal. Es decir que el empleo "en negro", al igual que en 2001, seguía afectando a la mayor parte de los ocupados. Los que lograron escapar, en cierta medida, a esta situación son los que se desempeñan en el sector azucarero, en el ámbito público, un grupo de la construcción y un trabajador ferroviario. Son casi todos varones, a excepción de una sola mujer que trabaja en el servicio doméstico.

En este contexto de fragilidad laboral adquirieron difusión los trabajos que se realizan como contraprestación a la percepción de planes sociales. Estos se orientan a tareas comunitarias, concentrándose principalmente en las mujeres, quienes participan en el sostenimiento de comedores, merenderos y talleres cooperativos. ${ }^{26}$ Se observa una fuerte valoración del trabajo comunitario relacionada con la presencia e inserción de una organización piquetera, el Centro Carballito, que promueve distintos proyectos y prácticas de autogestión. ${ }^{27}$ Esta orientación posibilitó que sus integrantes puedan pensarse y recrearse como trabajadores frente a las dificultades de inserción en el mercado de trabajo, principalmente las mujeres.

25 Se consideró a la población mayor de 14 años distinguiendo entre quienes se encuentran activos e inactivos.

26 Como resultado de la acción del movimiento piquetero, a fines de la década de 1990 en el marco de la crisis que atravesaba el país, las organizaciones lograron el control directo de los planes sociales, y pudieron orientar así la contraprestación exigida (4 horas diarias de trabajo), hacia el trabajo comunitario en los barrios (Svampa, 2005).

27 La autogestión en el ámbito laboral-productivo desde el punto de vista de esta organización refiere a la propia gestión de los trabajadores sobre su unidad de trabajo, sin capitalistas ni gerentes, desarrollando su propia gestión del proceso de trabajo, adoptando formas no jerárquicas. Se trataría entonces de una forma dinámica de organización económica-productiva alternativa a las propias del sistema capitalista. 
Con otra intencionalidad, el Estado utiliza los planes para bajar los índices de desocupación. Se considera "ocupados" a los beneficiarios de planes sociales aunque la ocupación sea transitoria, no cuente con los beneficios de la seguridad social y no reciban como retribución un salario sino una ayuda o beneficio (Olguín y Paez, 2005).

La cantidad de desocupados es significativa ya que el $20,5 \%$ declara estar en esta situación. Afecta de forma más acentuada a la franja etaria de los 21-30 años (46,7\%), encontrándose en este grupo mujeres principalmente. Cabe señalar que la problemática del desempleo afecta a un porcentaje incluso mayor de la población, teniendo en cuenta el $13 \%$ de ocupados en trabajo comunitario, es decir, beneficiarios sin trabajo que realizan una contraprestación por el plan social que perciben. Si bien hubo una disminución en relación a los niveles alcanzados en 2001, la desocupación seguía afectando a un número muy elevado de la población activa de la zona

Tabla 2. Población Activa Villa Muñecas Norte

\begin{tabular}{|c|c|c|c|c|c|}
\hline & PEA & & $\%$ Varones & $\%$ Mujeres & $\%$ Total \\
\hline & \multirow{7}{*}{ 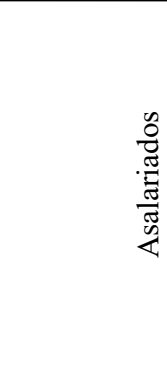 } & Trabajador ferroviario & 1,3 & 0 & 1,3 \\
\hline & & Construcción & 20,5 & 0 & 20,5 \\
\hline & & Empleo público & 3,8 & 0 & 3,8 \\
\hline & & $\begin{array}{l}\text { Trabajadores azucare- } \\
\text { ros }\end{array}$ & 7,7 & 0 & 7,7 \\
\hline & & Cosechero & 1,3 & 0 & 1,3 \\
\hline & & Empleo doméstico & & 14,1 & 14,1 \\
\hline & & Total & 34,6 & 14,1 & 48,7 \\
\hline & \multirow{4}{*}{$\begin{array}{l}\text { Traba- } \\
\text { jadores } \\
\text { por Cuenta } \\
\text { Propia }\end{array}$} & Changas (varias) & 9 & 0 & 9 \\
\hline & & $\begin{array}{l}\text { Kiosco/Venta comida, } \\
\text { ropa, cosméticos }\end{array}$ & & 3,8 & 3,8 \\
\hline & & Oficios & 5,1 & 0 & 5,1 \\
\hline & & Total & 14,1 & 3,8 & 17,9 \\
\hline \multirow{3}{*}{$\begin{array}{l}\text { Ocupados } \\
\text { Desocupados }\end{array}$} & $\begin{array}{l}\text { Trabajo Co- } \\
\text { munitario }\end{array}$ & Total & 1,3 & 11,5 & 12,8 \\
\hline & \multicolumn{2}{|c|}{ Total Ocupados } & 50 & 29,5 & 79,5 \\
\hline & \multicolumn{2}{|c|}{ Total Desocupados } & 12,8 & 7,7 & 20,5 \\
\hline Activos & \multicolumn{2}{|r|}{ Total } & 62,8 & 37,2 & 100 \\
\hline
\end{tabular}

\section{Fuente: Entrevistas semiestructuradas realizadas a una muestra de familias, 2011}

La mitad de la población inactiva está conformada por mujeres amas de casa siguiendo el grupo de estudiantes, con igual representación de varones y mujeres (Ver Tabla 3). En la categoría "otros" se refleja la situación de inactividad juvenil que se hace evidente en el grupo de los varones en tanto las mujeres se refugian en las tareas domésticas. 
Tabla 3. Población Inactiva en Villa Muñecas Norte

\begin{tabular}{|l|l|c|c|c|}
\hline \multirow{4}{*}{ Inactivos } & & Varones \% & Mujeres \% & Total \% \\
\cline { 2 - 5 } & Estudiantes & 12,8 & 12,8 & 25,6 \\
\cline { 2 - 5 } & Jubilados/Pensionados & 3,8 & 5,1 & 9 \\
\cline { 2 - 5 } & Amas de casa & & 51,3 & 51,3 \\
\cline { 2 - 5 } & Otros & 14,1 & & 14,1 \\
\cline { 2 - 5 } & Total & 30,8 & 69,2 & 100 \\
\hline
\end{tabular}

Fuente: Entrevistas semiestructuradas realizadas a una muestra de familias, 2011

\section{Lo que quedó del cierre de ingenios y la partida del tren: pobreza estruc- tural y nueva pobreza}

Villa Muñecas se pobló al influjo de la estación ferroviaria y las actividades vinculadas a sus funciones. La proximidad a los Talleres Ferroviarios de Tafí Viejo y al ingenio San José también aceleraron su crecimiento ya que los trabajadores tenían la oportunidad de asentarse cerca de la fuente de trabajo.

En ese momento el desarrollo ferroviario y azucarero parecía ofrecer un futuro promisorio a los habitantes de Villa Muñecas. Dichas posibilidades pudieron concretarse para gran parte de su población que logró ocuparse en estas actividades e iniciar un proceso de movilidad social ascendente. Pudieron acceder, en su gran mayoría, a la titularidad de los terrenos y avanzar en la construcción de las viviendas.

La crisis de la industria azucarera de la década de 1960 abrió un período de declive para los pobladores antiguos a la vez que determinó un proceso de nuevas ocupaciones en la zona. Surge en este momento Villa Muñecas Norte distinguiéndose del sector del barrio más antiguo. Estos hogares no tuvieron el mismo derrotero que los residentes más antiguos. Sus posibilidades de ingresar al mercado de trabajo formal fueron muy reducidas y la precariedad habitacional es una característica estructural.

El desmantelamiento del sistema ferroviario y el cierre de la Estación Muñecas en la década de 1990 afectaron a toda la población del barrio. En el sector tradicional provocó la pérdida de las fuentes de trabajo que, sumado a las transformaciones regresivas del mercado de trabajo, significó para muchos no volver a conseguir un empleo de características similares en lo relativo a estabilidad y condiciones laborales. Entraron, de esta manera, en la pendiente del deterioro social y laboral. Para los hogares de Villa Muñecas Norte, que ya atravesaban privaciones estructurales, significó la persistencia de las inserciones laborales precarias y mayores dificultades por el carácter estructural, y sus consecuencias, que adquiere la pobreza.

La impronta de un sector de la ciudad que cumplía una función central en la dinámica urbana, siendo un importante nodo en la red de transporte y por lo tanto de circulación y articulación de territorios, se desvaneció. El surgimiento de Villa Muñecas Norte en la década de 1960 fue una suerte de espejo que reflejó lo que tres décadas después sería el derrotero de esta población. 


\section{Bibliografía}

- Arriagada, C. (2000). "Pobreza en América Latina: Nuevos escenarios y desafíos de políticas para el hábitat urbano". Serie Medio Ambiente y Desarrollo, (27). Santiago de Chile: CEPAL/Naciones Unidas.

— Bergesio, L. y Golovanevsky, L. (2010). "Ferroviarios y Zapleros en Jujuy: De la seguridad social a la inestabilidad laboral". Revista de estudios regionales y mercado de trabajo, 6, pp.7-41.

— Bergesio, L.; Golovanevsky, L.; y Marcoleri, M. E. (2009). "Privatizaciones y mercado de trabajo: la venta de empresas públicas en Jujuy y sus consecuencias sobre el empleo”. En M. Lagos (dir.), Jujuy bajo el signo neoliberal. Política, economía y cultura en la década de los noventa. San Salvador de Jujuy: Unidad de Investigación en Historia Regional/EdiUnju.

- Bertotti, C. (2006). La producción de la muerte y las transformaciones del mundo de la vida en el barrio de Villa Muñecas. Tucumán: Instituto Gino Germani, Facultad de Ciencias Naturales e Instituto Miguel Lillo, Universidad Nacional de Tucumán.

- Boldrini, P. (2012). Producción participativa del hábitat popular en el área metropolitana de Tucumán. Tesis Doctoral. Tucumán, Argentina: Facultad de Filosofía y Letras, Universidad Nacional de Tucumán.

— Bolsi, A. y Ortiz de D’Arterio, P. (2001). Población y azúcar en el Noroeste argentino. Mortalidad infantil y transición demográfica durante el siglo XX. Tucumán: IEG-UNT.

— Centeno, R. (2013). "Informalidad en el proceso de urbanización de Villa Muñecas (Tucumán, Argentina)". Geographos, 4, (34).

- Ferrari, M. (1997). "El patrimonio ferroviario en el noroeste argentino. Tipologías arquitectónicas y asentamientos urbanos ferroviarios". Revista Transportes, servicios y telecomunicaciones, (12), pp. 170 -200.

— Gómez, A., Mario, S. y Olmos, F. (2003). "Índice de Privación Material de los Hogares (IPMH). Desarrollo y aplicación con datos del Censo Nacional de Población y Viviendas 2001". En: VII Jornadas Argentinas de Estudios de Población (AEPA). Universidad Nacional de Tucumán, Tafí del Valle. Tucumán. Tomo II: 1001-1017.

— Hintze, S. (1991), "Desocupación y economías del interior. La crisis en los centros urbanos". Revista Encrucijadas, pp. 60-65.

— Isla, A., Lacarrieu, M. y Henry S. (1999). Parando la olla. Transformaciones familiares, representaciones y valores en los tiempos de Menem. Buenos Aires: Grupo Editorial Norma.

- Katzman, R. (2001). "Seducidos y abandonados: el aislamiento social de los pobres urbanos”. Revista de la Cepal, (75), pp. 171-189.

- Katzman, R. (2003) "La dimensión espacial en las políticas de superación de la pobreza urbana”. CEPAL. Serie de Medio Ambiente y Desarrollo (59).

— Kessler, G. (2008) Infancias Vulnerables. Buenos Aires: American Joint. 
— Kessler, G. y Di Virgilio, M. (2008). "La nueva pobreza urbana: dinámica global, regional y argentina en las últimas dos décadas". Revista de la CEPAL, (95), pp. 31-50.

- Kessler G. y Espinoza V. (2003). "Movilidad social y trayectorias ocupacionales en Argentina: rupturas y algunas paradojas del caso de Buenos Aires". CEPAL, Santiago de Chile.

- La Gaceta (18/10/2011). "La destrucción del patrimonio ferroviario". Disponible en http:/www.lagaceta.com.ar/nota/460643/Opinion/destruccion-patrimonio-ferroviario.html [Consultado el 9/10/2013].

— Lenis, M. (2011). "El Centro Azucarero Argentino frente a la primera crisis azucarera de sobreproducción. Tensiones y conflictos, 1895-1897". Revista de Historia Americana y Argentina, (46), pp. 39-71.

- Lindenboim, J.(2005), El reparto de la torta. ¿Crecer repartiendo o repartir creciendo?, Capital Intelectual, Buenos Aires.

- Lindenboim, J. (2007), "La fuerza de trabajo en el siglo XX. Viejas y nuevas discusiones". En: Torrado, S. Población y bienestar en la Argentina del primero al segundo centenario. Una historia social del siglo XX, Tomo II, (pp. 285-323). Edhasa: Buenos Aires.

— Lo Vuolo, R., Barbeito, A., Pautassi, L. y Rodríguez, C. (2004), La pobreza... de la política contar la pobreza. Buenos Aires: Miño y Dávila.

— Longhi, F. (2012). "Pobreza en el Gran San Miguel de Tucumán en el año 2001. Un análisis de distribución espacial para una ciudad intermedia argentina". En L. Cid Ferreira y P. Arenas (Comps.). Violencias y derechos humanos. Estudios y debates en el Tucumán profundo (pp. 193 - 214).

- Merklen, D. (1995). Identidad y acción colectiva. Las ocupaciones ilegales de tierras urbanas en la Argentina de fin de siglo. Tesis Doctoral. Buenos Aires: Universidad Nacional de Buenos Aires, Maestría en Investigación en Ciencias Sociales.

— Minujin, A., López, N. (1994). "Nueva pobreza y exclusión: el caso argentino". Nueva sociedad, (131), pp. 88-105.

- Moreno, J. L. (2009). Éramos tan pobres... De la caridad a la Fundación Eva Perón. Buenos Aires: Editorial Sudamericana.

- Neffa, Julio (Coord.) (2005). Actividad, empleo y desempleo: conceptos y definiciones. Buenos Aires: Miño y Dávila.

- Schleh, E. (2006). La industria azucarera en su primer centenario (1821-1921). Buenos Aires: Sosa Paz.

- Paolasso, P. (2004). Los cambios en la distribución espacial de la población en la provincia de Tucumán durante el siglo XX. Tesis Doctoral. Tucumán: Facultad de Filosofía y Letras, Universidad Nacional de Tucumán.

— Paolasso, P. y Osatinsky, A. (2007). "Las transformaciones económicas y sociales de Tucumán en la década de 1960". En Actas VIII Encuentro Nacional de la Red de Economías Regionales en el Marco del Plan Fénix - I Jornadas Nacionales de Investigadores de las Economías Regionales. Disponible en http://www.econ. uba.ar/planfenix/index $2 . h t m$

— Osatinsky, A. y Paolasso, P. (2012). "La industria en la provincia de Tucumán: De la expansión azucarera a la desindustrialización”. En L. Bergesio y L. Golovane- 
vsky (Eds.). Industria y Sociedad. El sector manufacturero en Jujuy y Argentina. San Salvador de Jujuy: EdUNJu.

- Osatinsky, A. (2009). "Pobreza y transformaciones económicas en Catamarca y Tucumán(1980-2002)”. Población y Sociedad, (16), pp. 187-222.

- Svampa, M. (2005). La Sociedad Excluyente. La Argentina bajo el signo del neoliberalismo. Buenos Aires: Taurus.

- Olguín, J. y Páez, M. (2005). "Incidencia de los planes sociales en los indicadores del mercado laboral de San Luis, 2003-2004, un caso paradigmático". en Actas del Séptimo Congreso Nacional de Estudios del Trabajo.

— Vidarte Asorey, Verónica (2009). "Territorios y exclusión social en Buenos Aires. Análisis desde la comunicación/cultura". Cuaderno Urbano, 8(8), pp. 77-91.

—Zerda de Cainzo, H. E. (2002). Ciudades y pueblos de Tucumán. Aportes para su historia. Tucumán: EUNSTA.

- Ziccardi, A. (comp.) (2008). Procesos de urbanización de la pobreza y nuevas formas de exclusión social. Los retos de las políticas sociales de las ciudades latinoamericanas del siglo XXI. Bogotá: Siglo del Hombre Editores.

\section{Anexo}

Tabla 1. Condiciones Habitacionales en el sector tradicional de Villa Muńecas. 2001

\begin{tabular}{|c|c|}
\hline Tipo Vivienda & $\%$ \\
\hline Tipo A & 85,5 \\
\hline Tipo B & 8,6 \\
\hline Casilla & 4,5 \\
\hline Baño Instalado & \\
\hline $\mathrm{Si}$ & 94,4 \\
\hline $\mathrm{No}$ & 5,6 \\
\hline Gas natural & \\
\hline $\mathrm{Si}$ & 89,4 \\
\hline $\mathrm{No}$ & 10,6 \\
\hline
\end{tabular}

Fuente: Censo Nacional de Población, Hogares y Viviendas, 2001

Tabla 2. Acceso a los servicios urbanos en Villa Muńecas Norte, 2001

\begin{tabular}{|l|c|}
\hline & $\%$ \\
\hline Servicio regular recolección de residuos & 61,7 \\
\hline Existencia de transporte público & 100 \\
\hline Existencia de cloacas & 0,0 \\
\hline Existencia de red de agua corriente & 100 \\
\hline
\end{tabular}


Existencia de red eléctrica

Existencia de alumbrado público

Fuente: Censo Nacional de Población, Hogares y Viviendas, 2001

Tabla 3. Provisión de agua en Villa Muńecas Norte, 2009

\begin{tabular}{|c|c|}
\hline & $\%$ \\
\hline Con agua corriente intradomiciliaria & 72,6 \\
\hline Con agua corriente- Cańo único & 19,9 \\
\hline Cańo Público & 7,5 \\
\hline
\end{tabular}

Fuente: Resumen de Ronda CAPS Villa Muñecas

Tabla 4. Tipo Vivienda en Villa Muñecas Norte, 2001

\begin{tabular}{|c|c|}
\hline & $\%$ \\
\hline Casa tipo A & 43,7 \\
\hline Casa tipo B & 26,7 \\
\hline Rancho & 4,8 \\
\hline Casilla & 24,8 \\
\hline
\end{tabular}

Fuente: Censo Nacional de Población, Hogares y Viviendas, 2001

Tabla 5. Régimen de Tenencia en Villa Muñecas Norte, 2001

\begin{tabular}{|c|c|}
\hline & $\%$ \\
\hline Propietario de la vivienda y terreno & 42,7 \\
\hline Propietario sólo de la vivienda & 27,5 \\
\hline Inquilino & 1,2 \\
\hline Ocupante por préstamo & 7,7 \\
\hline Ocupante por trabajo & 0,7 \\
\hline Otra situación & 20,1 \\
\hline
\end{tabular}

Fuente: Censo Nacional de Población, Hogares y Viviendas, 2001

Tabla 6. Nivel educativo del Jefe/a de Hogar en Villa Muñecas Norte, 2001

\begin{tabular}{|c|c|}
\hline & $\%$ \\
\hline NO ASISTE y nunca asistió & 6,9 \\
\hline primaria incompleta & 27,0 \\
\hline primaria completa & 40,4 \\
\hline
\end{tabular}




\begin{tabular}{|c|c|}
\hline secundaria incompleta & 14,9 \\
\hline secundaria completa y más & 6,9 \\
\hline nivel superior incompleto & 1,5 \\
\hline nivel superior completo & 2,0 \\
\hline Subtotal no asiste & 99,8 \\
\hline ASISTE a la escuela primaria & 0,2 \\
\hline Asiste a la escuela secundaria & 0 \\
\hline Asiste a otro nivel & 0 \\
\hline Subtotal asiste & 0,2 \\
\hline TOTAL & 100 \\
\hline
\end{tabular}

Fuente: Censo Nacional de Población, Hogares y Viviendas, 2001

Tabla 7. Condición de actividad en Villa Muńecas Norte, 2001

\begin{tabular}{|c|c|c|c|}
\hline & & Varones $\%$ & Mujeres \% \\
\hline PEA & 62,0 & 58,0 & 42,0 \\
\hline PEI & 38,0 & 31,7 & 68,3 \\
\hline
\end{tabular}

Fuente: Censo Nacional de Población, Hogares y Viviendas. 2001

Tabla 8. Categoría ocupacional en Villa Muńecas Norte, 2001

\begin{tabular}{|c|c|}
\hline & Villa Muñecas \\
\hline Obrero/empleado sector público & 17,8 \\
\hline Obrero/empleado sector privado & 52,8 \\
\hline Patrón & 0,6 \\
\hline Trabajador por cuenta propia & 27,8 \\
\hline Trabajador familiar con sueldo & 0,0 \\
\hline Trabajador familiar sin sueldo & 1,1 \\
\hline
\end{tabular}

Fuente: Censo Nacional de Población, Hogares y Viviendas, 2001

Tabla 9. Calificación ocupacional en Villa Muñecas Norte, 2001

\begin{tabular}{|c|c|}
\hline & Villa Muñecas \\
\hline Calificación profesional & 0,6 \\
\hline Calificación técnica & 8,6 \\
\hline Calificación operativa & 55,8 \\
\hline No calificada & 30,8 \\
\hline Información insuficiente & 1,7 \\
\hline Calificación ignorada & 2,5 \\
\hline
\end{tabular}

Fuente: Censo Nacional de Población, Hogares y Viviendas, 2001 